\title{
REVIEW
}

\section{Clinical review: The liver in sepsis}

\author{
Nicolas Nesseler ${ }^{\dagger 1-3}$, Yoann Launey ${ }^{\dagger 1-3}$, Caroline Aninat ${ }^{2,3}$, Fabrice More ${ }^{2,3}$, Yannick Mallédant* ${ }^{* 1-3}$ and Philippe Seguin ${ }^{1-3}$
}

\begin{abstract}
During sepsis, the liver plays a key role. It is implicated in the host response, participating in the clearance of the infectious agents/products. Sepsis also induces liver damage through hemodynamic alterations or through direct or indirect assault on the hepatocytes or through both. Accordingly, liver dysfunction induced by sepsis is recognized as one of the components that contribute to the severity of the disease. Nevertheless, the incidence of liver dysfunction remains imprecise, probably because current diagnostic tools are lacking, notably those that can detect the early liver insult. In this review, we discuss the epidemiology, diagnostic tools, and impact on outcome as well as the pathophysiological aspects, including the cellular events and clinical picture leading to liver dysfunction. Finally, therapeutic considerations with regard to the weakness of the pertinent specific approach are examined.
\end{abstract}

\section{Introduction}

Severe sepsis and septic shock remain a thorny issue in public health care because of their high mortality rate, which has been reported to be between 30\% and 50\% $[1,2]$. Sepsis can evolve to multiple organ dysfunction syndrome (MODS), whose severity accounts for a high mortality rate. During sepsis, liver dysfunction is one of the MODS components and usually is associated with a poor prognosis but its precise incidence remains unclear. Whereas the liver plays a pivotal role in regulating a wide range of key metabolic, homeostatic, and host-defense activities, liver dysfunction is commonly viewed only as a consequence of shock and initial tissue hypoperfusion. In fact, the injured liver may be considered one of the main actors in the genesis and amplification of multiple organ failure. However, the lack of reliable diagnostic tools does

${ }^{\dagger}$ Contributed equally

*Correspondence: yannick.malledant@chu-rennes.fr

'Service d'Anesthésie-Réanimation 1, Hôpital Pontchaillou, 2 rue Henri Le Guilloux, 35033 Rennes, France

Full list of author information is available at the end of the article not allow detection of early liver dysfunction [3]. This concise overview aims to describe the epidemiology and prognostic value of liver dysfunction during sepsis, then to review the pathophysiological aspects and clinical features of liver dysfunction, and finally to propose a main therapeutic axis and perspectives on specific treatment.

\section{Septic liver dysfunction: incidence and definitions and impact on mortality}

The precise incidence of sepsis liver dysfunction remains difficult to establish because of the lack of a precise and consensus definition and the various observation times. Sands and colleagues [4] defined liver failure as a combination of a total bilirubin level of greater than $2 \mathrm{mg} / \mathrm{dL}$ $(>34 \mu \mathrm{mol} / \mathrm{L})$ and either an alkaline phosphatase or serum aminotransferase level of greater than twice the normal value. In a cohort of 1,342 episodes of sepsis syndrome, liver failure was present in $12 \%$ within 28 days of the onset of disease [4]. Conversely, using the International Classification of Diseases, Ninth Revision, Clinical Modification (ICD-9-CM) codes, Angus and colleagues [5] identified 192,980 cases of severe sepsis in seven states in the US and observed hepatic failure in only $1.3 \%$. However, this small incidence is explained by a strongly restrictive definition of liver dysfunction, including only acute and subacute necrosis of the liver and hepatic infarction. In a more recent clinical trial involving 312 patients in septic shock, acute liver failure was reported in $20 \%$ during the 72 -hour period of the study treatment [6]. This acute liver failure was defined by at least two of the following items: (a) bilirubin of greater than $2.5 \mathrm{mg} /$ $\mathrm{dL}(>43 \mu \mathrm{mol} / \mathrm{L})$, (b) serum alanine transaminase concentration of more than twice the upper limit, and (c) prothrombin time of greater than 1.5 times the control value or an international normalized ratio of greater than 1.5 [6]. The 2001 International Sepsis Definitions Conference recommended the use of scoring systems, such as the Sepsis-related Organ Failure Assessment (SOFA) score, the MODS score, or the Logistic Organ Dysfunction System (LODS) score [7]. All of these scores aim to quantify the degree of organ(s) dysfunction(s) over the course of sepsis and use bilirubin to assess and define liver dysfunction in addition to prothrombin time for the LODS score. In this conference, sepsis liver dysfunction 
was defined as a plasma total bilirubin of greater than $4 \mathrm{mg} / \mathrm{dL}(>70 \mu \mathrm{mol} / \mathrm{L})$ [7], but, interestingly, this cutoff value was not proposed by any of the cited scoring systems. Except for the early phase of severe sepsis/septic shock in which an acute elevation of serum aminotransferase levels (20-fold the upper limit of normal) permits the diagnosis of hypoxic hepatitis $(\mathrm{HH})$ [8], serum bilirubin could be assumed to be the most widely used and proposed biomarker to diagnose hepatic dysfunction/failure during sepsis. Thus, using the SOFA score, the French EPISEPSIS (EPIdemiology of SEPSIS) study group reported incidences of liver dysfunction (hepatic score of greater than 0 ) and liver failure (hepatic score of 3 or 4 ) of $46.6 \%$ and $6.3 \%$, respectively, in 541 patients with severe sepsis during the first 24 hours after admission to the intensive care unit (ICU) [9]. In the same population and with the same score, the PROWESS (Protein C Worldwide Evaluation in Severe Sepsis) trial reported incidences of liver dysfunction (hepatic score of 1 or 2) and liver failure (hepatic score of 3 or 4 ) of $35.6 \%$ and $2.75 \%$, respectively [10].

Developing the MODS score, Marshall and colleagues [11] evaluated the association of multiple hepatic biomarkers - bilirubin, albumin, alkaline phosphatase, aspartate and alanine aminotransferases (ASAT and ALAT, respectively), and lactate dehydrogenase (LDH) with ICU mortality rate in 692 patients to find the ideal descriptor of liver dysfunction. Unfortunately, neither a single biomarker nor a combination of variables could predict a mortality rate of greater than $50 \%$ at the highest increment of abnormality. Nevertheless, the authors selected bilirubin as the hepatic component of their score, arguing that bilirubin satisfied most of the criteria for the ideal descriptor of liver dysfunction; that is, bilirubin has a simple, routine, and reproducible dosage; is a comprehensive reflection of physiological liver function; and is readily evaluable in heterogeneous groups of critically ill patients [11]. However, the authors mentioned the failings of this criterion (that is, its lack of specificity and its inability to reflect the full spectrum of liver dysfunction and differentiate an acute response from a pre-existing organ chronic disease) [11].

Some authors have argued for the use of a dynamic test, such as the plasma indocyanine green (ICG) disappearance rate $\left(\mathrm{PDR}_{\mathrm{ICG}}\right)$, to assess liver function [12]. ICG is an organic anion that is exclusively eliminated by the liver and could estimate hepatic cell function and blood flow. This technique may detect septic liver dysfunction earlier than bilirubin and seems to correlate with patient outcome but is unable to distinguish the relative contribution of hepatic blood flow alterations to hepatocellular injury $[13,14]$. Moreover, an animal study questioned $\mathrm{PDR}_{\mathrm{ICG}}$ as a marker of liver cell function. In hyperdynamic porcine endotoxemia, $\mathrm{PDR}_{\mathrm{ICG}}$ failed to reflect liver dysfunction as neither hepatic blood flow nor $\mathrm{PDR}_{\mathrm{ICG}}$ exhibited any changes over time, whereas the cumulative bile flow, biliary ICG, and bicarbonate excretion fell dramatically [15].

Finally, assessing liver function among critically ill patients remains challenging, and neither static nor dynamic tests can be considered a gold standard. This issue could contribute to an underestimation of the frequency and importance of sepsis liver dysfunction during the course of sepsis. Because liver dysfunction is strongly associated with mortality in patients with sepsis, the ability to accurately assess liver function is of critical interest. The EPISEPSIS study group found that the persistence or development of liver failure in the 72-hour period after the onset of severe sepsis was strongly associated with outcome [9]. Furthermore, in the PROWESS trial, the lack of baseline liver dysfunction resolution or the development of new liver dysfunction during the first week of sepsis or both were associated with a lower 28-day survival rate [10]. Similarly, Hebert and colleagues [16] found a significant increased risk of death associated with hepatic failure in patients with sepsis. In the US, mortality was higher in patients meeting the criteria of severe sepsis with hepatic dysfunction based on the ICD-9-CM [5]. Finally, with respect to $\mathrm{HH}$, the presence of septic shock is an independent predictor of overall mortality [8]. Despite this important clinical issue, recent important trials on severe sepsis neglected to report specific data about liver function $[17,18]$. These data demonstrate the critical importance of the too-oftenneglected liver dysfunction in the outcome of severe sepsis and septic shock and the urgent need to improve the diagnosis and management of liver dysfunction.

\section{Pathophysiological aspects}

The pathophysiological aspects of liver dysfunction are complex and not yet well understood. Basically, the liver has a role in endotoxin and bacteria scavenging, detoxification, and synthesizing proteins for metabolic, immune, and coagulation functions. Several cells are involved in these processes: hepatocytes (HCs), Küpffer cells (KCs), and sinusoidal endothelial cells (SECs). To ensure these functions, liver perfusion, which represents $25 \%$ of the cardiac output, is accomplished mainly by portal venous blood flow. This flow is regulated by the hepatic arterial buffer response, which aims to compensate any reduction in portal blood flow [19].

During the course of septic shock, the liver contributes actively to host defense and tissue repair through crosstalk between hepatic cells and blood cells. HCs will shift their metabolic pathway toward upregulation of the inflammatory response, which is responsible for an increase in the synthesis of acute-phase proteins mediated predominantly by interleukin 6 (IL-6) [20]. This shift 
leads to increases in C-reactive protein, $\alpha$-1-antitrypsin, fibrinogen, prothrombin, and haptoglobin levels, whereas the hepatic production of albumin, transferring, and antithrombin is decreased. In addition, the upregulation of the acute-phase response inhibits the protein $C$ pathway, and the profound changes in the balance of coagulation factors result in pro-coagulant activity in sepsis. Moreover, glucose metabolism is significantly altered because of increases in glycogenolysis and gluconeogenesis [21], and liver hypermetabolism, such as increased amino-acid uptake, occurs [22]. In addition, the metabolic changes and inflammatory response lead to a decrease in biotransformation liver function, especially a reduction in cytochrome P450 activity. Thus, the elimination of endobiotic and xenobiotic compounds is considerably impaired [23,24]. In contrast, KCs are key cells involved in scavenging bacteria and endotoxin. The liver harbors approximately $80 \%$ of all macrophages in the human body as resident $\mathrm{KCs}$ [25]. Indeed, endotoxin clearance was impaired in the case of underlying liver disease, which could explain a higher susceptibility of the host to infection [26]. KCs can produce various pro-inflammatory mediators, including tumor necrosis factor-alpha (TNF- $\alpha)$, known to be largely involved in systemic inflammatory response syndrome (SIRS), the enhancement of hepatic acute-phase proteins, and the production of nitric oxide (NO) [27]. KCs also interact with blood cell components (platelets, erythrocytes, and leukocytes), promoting neutrophil recruitment in the sinusoids and enhancing the pro-inflammatory response [3]. Hepatic injury can worsen through the adhesion of neutrophils to SECs, promoting thrombi formation in the sinusoids and impairing liver microvascular perfusion [3].

\section{Cellular and molecular effects}

Except for $\mathrm{HH}$, several experimental data argue for an early and insidious liver dysfunction during the initial phase of sepsis. To date, however, this early liver dysfunction has not been easily detectable in clinical practice.

Exogenous mediators, notably lipopolysaccharide (LPS), have direct and indirect cytotoxic effects on $\mathrm{HCs}$ and trigger $\mathrm{HC}$ metabolic changes [28-30]. Moreover, several cytokines that can induce hepatocellular dysfunction are produced by $\mathrm{KCs}$ in response to endotoxin (Table 1) [31]. Among them, TNF- $\alpha$ is considered to be the cornerstone cytokine of SIRS development and can directly stimulate HCs to induce IL- 6 production. IL-6 is considered the main cytokine implicated in the liver inflammatory response and is also produced by SECs [32], KCs, and HCs after LPS stimulation [29]. In combination with IL- $1 \beta$ and TNF- $\alpha$, IL- 6 is widely involved in the stimulation of acute-phase protein production [3]. IL-6 can also induce the activation and release of transforming growth factor-beta, which counteracts the extension of the inflammatory response and thus alters the response toward potential immunosuppression [33]. Notably, recent experimental data suggest that hepcidin most predominantly secreted by the HCs can modulate acute inflammatory response by the suppression of IL-6 and TNF- $\alpha$ [34]. As cholestatic liver injury is associated with a downregulation of hepcidin levels, hepcidin pretreatment significantly reduced $\mathrm{HC}$ pro-inflammatory cytokines, leading to reduced early lethality in mice receiving LPS [35].

Another major cytokine responsible for the hepatocellular dysfunction is IL-18. This cytokine, secreted by KCs after LPS treatment, plays a critical role in LPSinduced liver toxicity. Thus, LPS can induce the production of a pro-IL-18 cytokine that needs to be cleaved into a biologically active form by caspase-1-dependent processing. After maturation, IL-18 causes the secretion by hepatic lymphocytes of interferon-gamma (IFN- $\gamma$ ), which is itself responsible for direct liver injury via $\mathrm{HC}$ apoptosis, and a second elevation of TNF- $\alpha$ [36]. Interestingly, IFN- $\gamma$ is also able to upregulate the expression of the Toll-like receptor 4 [37], which participates in an inflammatory hyper-reactive response to LPS, leading to a potentially harmful, whole-body inflammation response. Like cytokines, reactive oxygen species participate in the liver response to LPS. Despite controversies, during the early stage of sepsis, $\mathrm{NO}$ is thought to be responsible for the decreased vascular resistance to maintain adequate tissue perfusion, and during the later course of sepsis, excessive NO release is responsible for generalized hypotension. The beneficial effects of NO seem to lie in the subtle control of its production by inducible NO synthase and constitutively expressed NO synthase by KCs, HCs, and SECs [38]. The functions of NO include the maintenance of vascular integrity and hepatosplanchnic blood flow, relaxation of vascular smooth muscles, and inhibition of leukocyte adherence to endothelial cells and platelet aggregation. Low NO levels could be hepatoprotective in sepsis [39]. In response to the vasodilator effect of NO, circulating endothelin-1, a strong vasoconstrictor that is involved in the dramatic reduction of blood flow in liver sinusoids, is increased. By stimulating the shift of perisinusoidal Ito cells (also called stellate cells) from their storage phenotype toward their activated contractile state, endothelin-1 reduces the diameters of hepatic sinusoid vessels [40].

Lipid mediators, such as platelet-activating factor and arachidonic acid metabolites of cyclooxygenase or lipoxygenase, can also promote direct liver injury by an imbalance in their production [30,41]. For example, thromboxane A2 may contribute to platelet aggregation and vasoconstriction, but its contribution is probably less than that of endothelin-1, which can more potently reduce blood flow through the hepatic sinusoids [42]. 
Table 1. Effects of cytokines during liver sepsis

\begin{tabular}{llc}
\hline Cytokines & Effects of cytokines & References \\
\hline TNF- $a$ & Pro-inflammatory response and stimulation of IL-6 production by HCs & [31] \\
IL-6 & Pro-inflammatory response, stimulation of acute-phase proteins, and activation and release of TGF- $\beta$ & {$[29,31-33]$} \\
IL-1 $\beta$ & Pro-inflammatory response and synergistic action with TNF- $a$ & {$[3,31]$} \\
TGF- $\beta$ & Anti-inflammatory response and counteracting of the extension of inflammatory response & {$[33]$} \\
IL-18 & LPS-induced liver toxicity and secretion of IFN- $\gamma$ & {$[36]$} \\
IFN- $\gamma$ & HC apoptosis, elevation of TNF- $a$, and upregulation of CD14 & {$[30]$} \\
IL-10 & Anti-inflammatory response and downregulation of LPS-induced IL-6 release & {$[32]$} \\
\hline
\end{tabular}

HC, hepatocyte; IFN- - , interferon-gamma; IL, interleukin; LPS, lipopolysaccharide; TGF- $\beta$, transforming growth factor-beta; TNF-a, tumor necrosis factor-alpha.

Interestingly, an increase in gut-released norepinephrine during the early stage of sepsis has recently been shown to be involved in hepatocellular dysfunction. The activation of the $\alpha 2$-adrenergic pathway in $\mathrm{KCs}$ by this catecholamine leads to the secretion of TNF- $\alpha$, IL-1 $\beta$, and IL-10 $[43,44]$.

\section{Clinical events}

At the bedside, liver dysfunction is non-univocal, and two schematic clinical features may be observed: $\mathrm{HH}$ mainly as a result of an extrahepatic vascular event and jaundice or sepsis-induced cholestasis as the consequence of an insidious and slow intrahepatic injury. Despite sharing some similarities, these features are quite different.

\section{Hypoxic hepatitis}

$\mathrm{HH}$ is defined according to three criteria [8,45]: (a) a clinical setting of cardiac, circulatory, or respiratory failure; (b) a dramatic and transient increase in serum aminotransferase activity (at least 20-fold higher than the upper limit of normal); and (c) the exclusion of other putative causes of liver cell necrosis. Septic shock with $\mathrm{HH}$ represents up to $32 \%$ of all $\mathrm{HH}$ cases in ICU patients [8] and can lead to fulminant hepatic failure. In cardiogenic shock, $\mathrm{HH}$ is secondary to decreased cardiac output and oxygen delivery. However, in septic shock, splanchnic blood flow and cardiac output are increased but not sufficient to counterbalance the high demands for oxygen and the inability of liver cells to extract oxygen [46]. Moreover, vascular mechanisms of defense against portal blood flow reduction are altered, especially the hepatic arterial buffer response [19]. Compromised liver hemodynamics, however, do not always lead to $\mathrm{HH}$. Endotoxins and pro-inflammatory mediators could have an important role in potentiating $\mathrm{HH}$ development. Although the mechanisms are not fully understood, $\mathrm{HH}$ could result from the reoxygenation phase caused by the ischemia/reperfusion phenomenon, including oxidant stress, early activation of KCs, and secondary recruitment and activation of systemic neutrophils [47]. The enzymatic pattern of $\mathrm{HH}$ starts with sharp but unsustained increases in ASAT, ALAT, and LDH levels 24 hours after the initiation of shock; decreasing levels are observed 2 or 3 days later, and normal levels are reached in approximately 15 days. The other hallmark of $\mathrm{HH}$ is an early and dramatic drop in prothrombin levels [47], which is responsible for hemorrhagic syndrome. A serum creatinine level of greater than $20 \mathrm{mg} / \mathrm{L}(>177 \mu \mathrm{mol} / \mathrm{L})$ was observed in $65 \%$ of $\mathrm{HH}$ but probably reflects the renal impairment caused by the hemodynamic failure $[8,48]$. In addition, a delayed elevation of bilirubin in $\mathrm{HH}$ is described but, in most cases, without visible jaundice.

\section{Jaundice or sepsis-induced cholestasis}

Clinical jaundice is usually associated with severe infections such as pneumonia, Gram-negative bacterial sepsis, or septic shock $[49,50]$. An observational study conducted in 283 critically ill patients revealed sepsis as one of the most important promoters of hyperbilirubinemia ( $>2 \mathrm{mg} / \mathrm{dL}$ or $34 \mu \mathrm{mol} / \mathrm{L}$ ) [51]. Commonly during sepsis, increased bilirubin levels are a late event in the course of multiorgan dysfunction [52]. In a large cohort of ICU patients, $11 \%$ had an 'early' hepatic dysfunction defined as a bilirubin concentration of greater than $2 \mathrm{mg} /$ $\mathrm{dL}(>34 \mu \mathrm{mol} / \mathrm{L})$ within 48 hours of admission [51]. Liver histological studies in patients with bacteremic jaundiced showed a predominant intrahepatic cholestasis [53]. Among their various functions, bile and bile acids are involved mainly in gut trophicity and gut barrier integrity [54]. Their transport and excretion into the canalicular duct are highly dependent on energy and oxygen. HCs are dual-polarity cells that have both basolateral and canalicular membranes. Bile formation is an active osmotic process that involves the crossing of organic and inorganic molecules through the canalicular membrane followed by passive movement of water. Bile formation also requires the correct functioning of integral membrane proteins (that is, an intact cytoskeleton, tight junctions, and intracellular signal transduction) [55]. First, unconjugated bilirubin uptake is promoted at the basolateral membrane and conjugated bilirubin transported across the canalicular membrane by an 
energy-dependent multidrug-resistant protein 2 (MRP2) pump [56] (Figure 1a). Basolateral membranes facilitate bile acid transport into HCs: unconjugated bile acids are taken up by members of the solute carrier organic anion transporter family (SLC21), formerly known as organic anion-transporting polypeptides (OATPs), and conjugated bile acids are transported into HCs mainly by the sodium taurocholate cotransporting polypeptide (NTCP), which is helped by an ATP-dependent $\mathrm{Na} / \mathrm{K} /$ ATPase pump. Efflux systems for bile acids also exist at basolateral poles. At the canalicular membrane, bile acids are excreted mainly by an ATP-dependent bile salt export pump (BSEP) [57]. Furthermore, a bile acid-independent bile flow (BAIBF) participates in bile flow generation and involves the active secretion of inorganic electrolytes, such as bicarbonate. During sepsis, most of these steps can be impaired because of a lack of energy such as hypoxia or hypoperfusion or both [56], and BSEP is a major bile flow-limiting factor at the canalicular level (Figure 1b). Endotoxins or pro-inflammatory cytokines cause direct impairment of bile flow through alterations of both transcriptional and post-transcriptional gene expression of bile acid transporters, resulting in the downregulation of transporter proteins [53]. Cytokines promote oxidant stress that results in the inhibition of cAMP-dependent transport function [58] and BAIBF. Finally, endotoxins severely alter the cytoskeletal architecture of HCs contributing to the disturbance of bile flow (Figure 1b) [55]. All of these alterations contribute to hyperbilirubinemia associated with an intrahepatic cholestasis, the severity of which likely depends on the intensity of the impaired steps in bile formation. The reduction of bile flow or the absence of intraluminal bile can lead to intestinal mucosal atrophy [54] and then deprives the gut of its bacteriostatic neutralizing effects and promotes an increase of endotoxin blood levels $[59,60]$. This endotoxin release participates in direct bile flow reduction and thus might enter the liver in a vicious circle promoting MODS.

\section{Therapeutic considerations}

No specific therapeutics for liver sepsis dysfunction/ failure are currently available. Nevertheless, a set of recommendations could be given from the perspective of liver dysfunction/failure. Thus, sepsis liver management relies first on early goal-directed resuscitation as recommended (that is, early antibiotic therapy and infection source control, fluid resuscitation, and vasopressor support to restore perfusion in the liver and other organs as well as support for the associated organ failure) [61]. Indeed, an appropriate hemodynamic restoration permits the restoration of liver perfusion and is an essential step in avoiding liver dysfunction. Interestingly, experimental data suggest that catecholamines could have an effect in the inflammatory response and participate in hepatic dysfunction [29]. Corticosteroid use in septic shock is still debated, but with respect to the liver, experimental data suggest that they may have an immunomodulation effect on sepsis-induced cholestasis through the induction of hepatobiliary transporters and restoration of bile transport [62]. Moreover, in the CORTICUS (Corticosteroid Therapy of Septic Shock) study, hydrocortisonetreated patients demonstrated a faster improvement in liver failure (SOFA hepatic score of 3 or 4 ) during the first week $(P<0.0001)$ [63]. However, at present, the use of corticosteroids cannot be recommended for the treatment of sepsis-induced hepatic dysfunction.

For hemodynamically stable patients with a functioning gastrointestinal tract, early enteral feeding has become a recommended standard of care [64]. Therefore, because of the potential favorable effects on the gut barrier and oxygenation, enteral nutrition (EN) should be preferred in patients with jaundice $[65,66]$. EN has also been associated with decreased infection rates and fewer metabolic complications in liver disease and after liver transplant compared with parenteral nutrition [67]. Furthermore, EN stimulates bile acid secretion and promotes the resurgence of the enterohepatic cycle [68]. Because hypoglycemia is a frequent event in liver failure, the close monitoring of glycemic levels and careful glucose administration are required and aggressive insulin therapy should then be used with caution [69].

Drugs potentially inducing cholestasis or hepatocellular damage - for example, acetaminophen, non-steroid antiinflammatory drugs, benzodiazepines, phenytoin, sodium valproate, amiodarone, antifungals, rifampicin, isoniazid, and fusidic acid - should be avoided or at least used with caution [70]. Moreover, recent genomic studies suggest that polymorphisms in genes involved in molecule metabolism could be an interesting way to define groups of patients at risk of drug-induced liver toxicity [71]. Because ursodeoxycholic acid, a chelator of bile acids, has cytoprotective and immunomodulatory effects, it has been used to treat cholestatic diseases (for example, primary biliary cirrhosis). These molecules could be considered for sepsis-induced cholestasis [72], but no data currently support such an assertion. Finally, extracorporeal liver devices have been proposed to remove endotoxins, such as by hemoperfusion with a polymixin B membrane, or to remove albumin-bound toxins, such as by the molecular adsorbents recirculating system (MARS ${ }^{\circ}$; Gambro Hospal, Peterborough, UK). Their effectiveness and safety have yet to be demonstrated.

\section{Conclusions}

Sepsis-induced liver dysfunction is a frequent event and is strongly associated with mortality. During the past few decades, its pathophysiology, including hypoxic and 


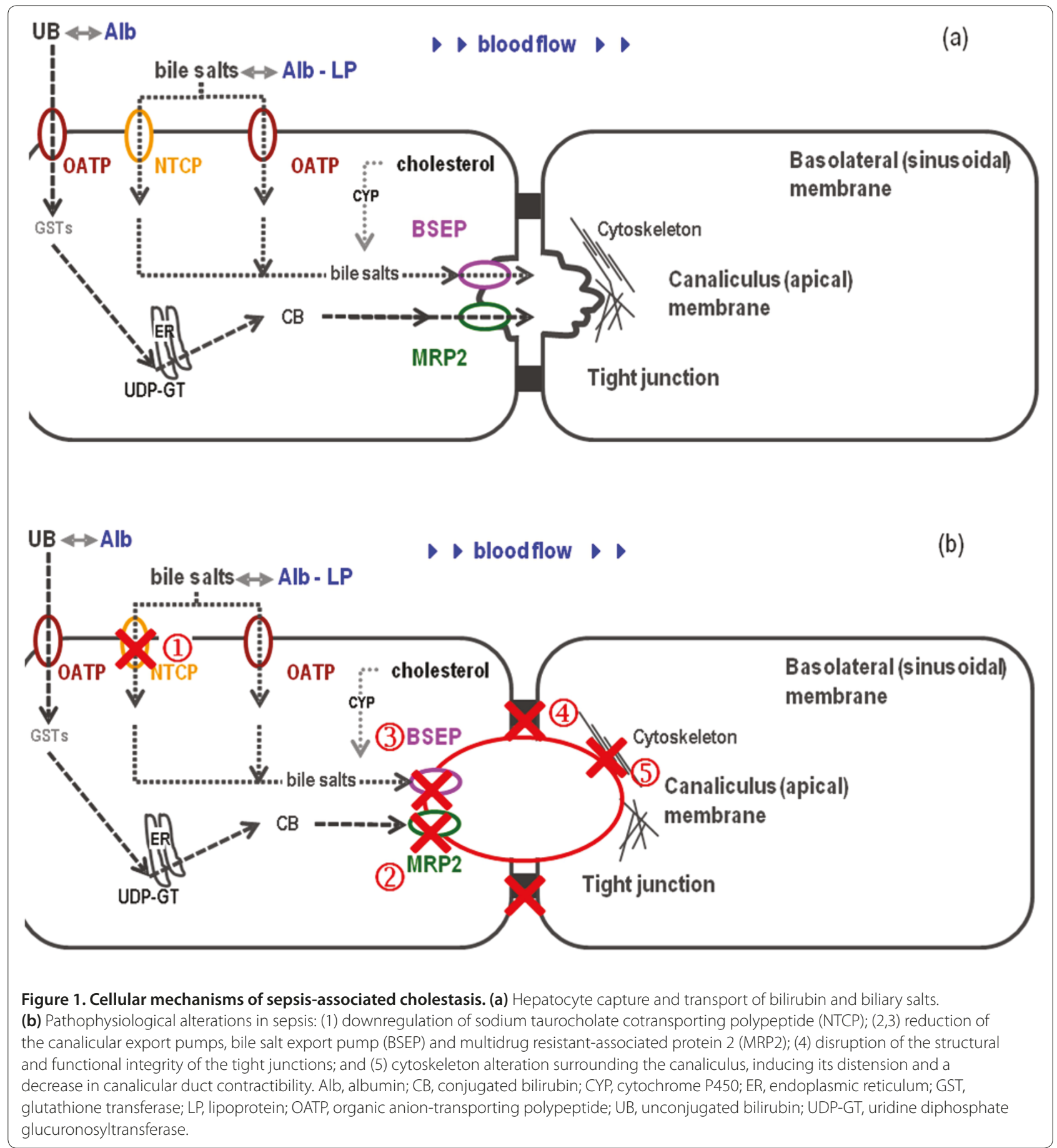

cholestasis aspects, has been better understood. However, the tools to diagnose liver dysfunction earlier and more accurately remain limited. At this time, the treatment of liver dysfunction is included only in the general therapeutic steps on sepsis syndrome management. An earlier and better identification of patients with liver dysfunction is warranted and may be the way to evaluate new therapeutic strategies and further improve the prognosis of sepsis.

\section{Abbreviations}

ALAT, alanine aminotransferase; ASAT, aspartate aminotransferase; BAIBF, bile acid-independent bile flow; BSEP, bile salt export pump; EN, enteral nutrition; EPISEPSIS, EPIdemiology of SEPSIS; HC, hepatocyte; HH, hypoxic hepatitis; ICD-9-CM, International Classification of Diseases, Ninth Revision, Clinical Modification; ICG, indocyanine green; ICU, intensive care unit; IFN- - , interferongamma; IL, interleukin; KC, Küpffer cell; LDH, lactate dehydrogenase; LODS, logistic organ dysfunction score; LPS, lipopolysaccharide; MODS, multiple organ dysfunction syndrome; $\mathrm{NO}$, nitric oxide; $\mathrm{PDR}_{\mathrm{ICG}}$, plasma disappearance rate of indocyanine green; PROWESS, Protein C Worldwide Evaluation in Severe Sepsis; SEC, sinusoidal endothelial cell; SIRS, systemic inflammatory 
response syndrome; SOFA, sepsis-related organ failure assessment; TNF-a, tumor necrosis factor-alpha.

\section{Competing interests}

The authors declare that they have no competing interests.

\section{Author details}

'Service d'Anesthésie-Réanimation 1, Hôpital Pontchaillou, 2 rue Henri Le Guilloux, 35033 Rennes, France. ${ }^{2}$ INSERM UMR-S 991, Hôpital Pontchaillou, 2, rue Henri Le Guilloux, 35033 Rennes, France. ${ }^{3}$ Université de Rennes 1, Faculté de Médecine, 2 avenue du Professeur Léon Bernard, 35033 Rennes, France.

Published: 30 October 2012

\section{References}

1. Blanco J, Muriel-Bombín A, Sagredo V, Taboada F, Gandía F, Tamayo L, Collado J, García-Labattut A, Carriedo D, Valledor M, De Frutos M, López M, Caballero A, Guerra J, Alvarez B, Mayo A, Villar J: Incidence, organ dysfunction and mortality in severe sepsis: a Spanish multicentre study. Crit Care 2008, 12:R158.

2. Martin GS, Mannino DM, Eaton S, Moss M: The epidemiology of sepsis in the United States from 1979 through 2000. N Engl J Med 2003, 348:1546-1554

3. Dhainaut JF, Marin N, Mignon A, Vinsonneau C: Hepatic response to sepsis: interaction between coagulation and inflammatory processes. Crit Care Med 2001, 29:S42-47.

4. Sands KE, Bates DW, Lanken PN, Graman PS, Hibberd PL, Kahn KL, Parsonnet J, Panzer R, Orav EJ, Snydman DR, Black E, Schwartz JS, Moore R, Johnson BLJ, Platt R: Epidemiology of sepsis syndrome in 8 academic medical centers. JAMA 1997, 278:234-240.

5. Angus DC, Linde-Zwirble WT, Lidicker J, Clermont G, Carcillo J, Pinsky MR: Epidemiology of severe sepsis in the United States: analysis of incidence, outcome, and associated costs of care. Crit Care Med 2001, 29:1303-1310.

6. Bakker J, Grover R, McLuckie A, Holzapfel L, Andersson J, Lodato R, Watson D, Grossman S, Donaldson J, Takala J: Administration of the nitric oxide synthase inhibitor NG-methyl-L-arginine hydrochloride (546C 88 ) by intravenous infusion for up to 72 hours can promote the resolution of shock in patients with severe sepsis: results of a randomized, doubleblind, placebo-controlled multicenter study (study no. 144-002). Crit Care Med 2004, 32:1-12

7. Levy MM, Fink MP, Marshall JC, Abraham E, Angus D, Cook D, Cohen J, Opal SM, Vincent J, Ramsay G: 2001 SCCM/ESICM/ACCP/ATS/SIS International Sepsis Definitions Conference. Crit Care Med 2003, 31:1250-1256.

8. Fuhrmann V, Kneidinger N, Herkner H, Heinz G, Nikfardjam M, Bojic A, Schellongowski P, Angermayr B, Kitzberger R, Warszawska J, Holzinger U, Schenk P, Madl C: Hypoxic hepatitis: underlying conditions and risk factors for mortality in critically ill patients. Intensive Care Med 2009, 35:1397-1405.

9. Brun-Buisson C, Meshaka P, Pinton P, Vallet B: EPISEPSIS: a reappraisal of the epidemiology and outcome of severe sepsis in French intensive care units. Intensive Care Med 2004, 30:580-588.

10. Vincent JL, Angus DC, Artigas A, Kalil A, Basson BR, Jamal HH, Johnson G, Bernard GR, for the Recombinant Human Activated Protein C Worldwide Evaluation in Severe Sepsis (PROWESS) study group: Effects of drotrecogin alfa (activated) on organ dysfunction in the PROWESS trial. Crit Care Med 2003, 31:834-840

11. Marshall JC, Cook DJ, Christou NV, Bernard GR, Sprung CL, Sibbald WJ: Multiple organ dysfunction score: a reliable descriptor of a complex clinical outcome. Crit Care Med 1995, 23:1638-1652.

12. Sakka SG: Assessing liver function. Curr Opin Crit Care 2007, 13:207-214

13. Kimura S, Yoshioka T, Shibuya M, Sakano T, Tanaka R, Matsuyama S: Indocyanine green elimination rate detects hepatocellular dysfunction early in septic shock and correlates with survival. Crit Care Med 2001, 29:1159-1163.

14. Kortgen A, Paxian M, Werth M, Recknagel P, Rauchfuss F, Lupp A, Krenn CG, Müller D, Claus RA, Reinhart K, Settmacher U, Bauer M: Prospective assessment of hepatic function and mechanisms of dysfunction in the critically ill. Shock 2009, 32:358-365.

15. Stehr A, Ploner F, Traeger K, Theisen M, Zuelke C, Radermacher P, Matejovic M: Plasma disappearance of indocyanine green: a marker for excretory liver function? Intensive Care Med 2005, 31:1719-1722.

16. Hebert PC, Drummond AJ, Singer J, Bernard GR, Russell JA: A simple multiple system organ failure scoring system predicts mortality of patients who have sepsis syndrome. Chest 1993, 104:230-235.

17. Abraham E, Laterre P, Garg R, Levy H, Talwar D, Trzaskoma BL, François B, Guy JS, Brückmann M, Rea-Neto A, Rossaint R, Perrotin D, Sablotzki A, Arkins N, Utterback BG, Macias WL: Drotrecogin alfa (activated) for adults with severe sepsis and a low risk of death. N Engl J Med 2005, 353:1332-1341.

18. Russell JA, Walley KR, Singer J, Gordon AC, Hébert PC, Cooper DJ, Holmes CL, Mehta S, Granton JT, Storms MM, Cook DJ, Presneill JJ, Ayers D: Vasopressin versus norepinephrine infusion in patients with septic shock. N Engl J Med 2008, 358:877-887.

19. Lautt WW: Mechanism and role of intrinsic regulation of hepatic arterial blood flow: hepatic arterial buffer response. Am J Physiol 1985, 249:G549-556.

20. Vary TC, Kimball SR: Regulation of hepatic protein synthesis in chronic inflammation and sepsis. Am J Physiol 1992, 262:C445-452.

21. Casteleijn E, Kuiper J, Van Rooij HC, Kamps JA, Koster JF, Van Berkel TJ: Endotoxin stimulates glycogenolysis in the liver by means of intercellular communication. J Bio/ Chem 1988, 263:6953-6955.

22. Meinz H, Lacy DB, Ejiofor J, McGuinness OP: Alterations in hepatic gluconeogenic amino acid uptake and gluconeogenesis in the endotoxin treated conscious dog. Shock 1998, 9:296-303.

23. Harbrecht BG, Frye RF, Zenati MS, Branch RA, Peitzman AB: Cytochrome P-450 activity is differentially altered in severely injured patients. Crit Care Med 2005, 33:541-546.

24. Jacob A, Zhou M, Wu R, Wang P: The role of hepatic cytochrome P-450 in sepsis. Int J Clin Exp Med 2009, 2:203-211.

25. Katz S, Jimenez MA, Lehmkuhler WE, Grosfeld JL: Liver bacterial clearance following hepatic artery ligation and portacaval shunt. J Surg Res 1991, 51:267-270.

26. Nakatani Y, Fukui H, Kitano H, Nagamoto I, Tsujimoto T, Kuriyama S, Kikuchi E, Hoppou K, Tsujii T: Endotoxin clearance and its relation to hepatic and renal disturbances in rats with liver cirrhosis. Liver 2001, 21:64-70.

27. Fong YM, Marano MA, Moldawer LL, Wei H, Calvano SE, Kenney JS, Allison AC, Cerami A, Shires GT, Lowry SF: The acute splanchnic and peripheral tissue metabolic response to endotoxin in humans. J Clin Invest 1990, 85:1896-1904.

28. Migita K, Abiru S, Nakamura M, Komori A, Yoshida Y, Yokoyama T, Daikoku M, Ueki T, Takii Y, Yano K, Yastuhashi H, Eguchi K, Ishibashi H: Lipopolysaccharide signaling induces serum amyloid $A(S A A)$ synthesis in human hepatocytes in vitro. FEBS Lett 2004, 569:235-239.

29. Aninat $C$, Seguin P, Descheemaeker P, Morel F, Malledant Y, Guillouzo A: Catecholamines induce an inflammatory response in human hepatocytes. Crit Care Med 2008, 36:848-854.

30. Ring A, Stremmel W: The hepatic microvascular responses to sepsis. Semin Thromb Hemost 2000, 26:589-594.

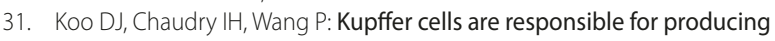
inflammatory cytokines and hepatocellular dysfunction during early sepsis. J Surg Res 1999, 83:151-157.

32. Knolle PA, Löser E, Protzer U, Duchmann R, Schmitt E, zum Büschenfelde KH, Rose-John S, Gerken G: Regulation of endotoxin-induced IL-6 production in liver sinusoidal endothelial cells and Kupffer cells by IL-10. Clin Exp Immunol 1997, 107:555-561.

33. Ayala A, Knotts JB, Ertèl W, Perrin MM, Morrison MH, Chaudry $I \mathrm{H}$ : Role of interleukin 6 and transforming growth factor-beta in the induction of depressed splenocyte responses following sepsis. Arch Surg 1993, 128:8994; discussion 94-95.

34. De Domenico I, Zhang TY, Koening CL, Branch RW, London N, Lo E, Daynes RA, Kushner JP, Li D, Ward DM, Kaplan J: Hepcidin mediates transcriptional changes that modulate acute cytokine-induced inflammatory responses in mice. J Clin Invest 2010, 120:2395-2405.

35. Huang Y, Yang Y, Tiao M, Kuo H, Huang L, Chuang J: Hepcidin protects against lipopolysaccharide-induced liver injury in a mouse model of obstructive jaundice. Peptides 2012, 35:212-217.

36. Tsutsui H, Matsui K, Kawada N, Hyodo Y, Hayashi N, Okamura H, Higashino K, Nakanishi K: IL-18 accounts for both TNF-alpha- and Fas ligand-mediated hepatotoxic pathways in endotoxin-induced liver injury in mice. J Immunol 1997, 159:3961-3967.

37. Bosisio D, Polentarutti N, Sironi M, Bernasconi S, Miyake K, Webb GR, Martin MU, Mantovani A, Muzio M: Stimulation of toll-like receptor 4 expression in human mononuclear phagocytes by interferon-gamma: a molecular basis for priming and synergism with bacterial lipopolysaccharide. Blood 2002, 99:3427-3431. 
38. Wong JM, Billiar TR: Regulation and function of inducible nitric oxide synthase during sepsis and acute inflammation. Adv Pharmacol 1995, 34:155-170.

39. Pastor CM, Losser MR, Payen D: Nitric oxide donor prevents hepatic and systemic perfusion decrease induced by endotoxin in anesthetized rabbits. Hepatology 1995, 22:1547-1553.

40. Sakamoto M, Ueno T, Kin M, Ohira H, Torimura T, Inuzuka S, Sata M, Tanikawa $\mathrm{K}$ : Ito cell contraction in response to endothelin-1 and substance $P$. Hepatology 1993, 18:978-983.

41. Wang JH, Redmond HP, Watson RW, Condron C, Bouchier-Hayes D: Induction of heat shock protein 72 prevents neutrophil-mediated human endothelial cell necrosis. Arch Surg 1995, 130:1260-1265.

42. Bauer M, Zhang JX, Bauer I, Clemens MG: ET-1 induced alterations of hepatic microcirculation: sinusoidal and extrasinusoidal sites of action. Am J Physiol 1994, 267:G143-149.

43. Miksa M, Das P, Zhou M, Wu R, Dong W, Ji Y, Goyert SM, Ravikumar TS, Wang P: Pivotal role of the alpha(2A)-adrenoceptor in producing inflammation and organ injury in a rat model of sepsis. PLOS ONE 2009, 4:e5504.

44. Zhang F, Wu R, Qiang X, Zhou M, Wang P: Antagonism of alpha2Aadrenoceptor: a novel approach to inhibit inflammatory responses in sepsis. J Mol Med 2010, 88:289-296.

45. Henrion J, Schapira M, Luwaert R, Colin L, Delannoy A, Heller FR: Hypoxic hepatitis: clinical and hemodynamic study in 142 consecutive cases. Medicine (Baltimore) 2003, 82:392-406.

46. Dahn MS, Lange P, Lobdell K, Hans B, Jacobs LA, Mitchell RA: Splanchnic and total body oxygen consumption differences in septic and injured patients. Surgery 1987, 101:69-80.

47. Henrion J: Hypoxic hepatitis. Liver Int 2011 Oct 10 [Epub ahead of print].

48. Raurich JM, Llompart-Pou JA, Ferreruela M, Colomar A, Molina M, Royo C, Ayestarán I, Ibáñez J: Hypoxic hepatitis in critically ill patients: incidence, etiology and risk factors for mortality. J Anesth 2011, 25:50-56.

49. Gimson AE: Hepatic dysfunction during bacterial sepsis. Intensive Care Med 1987, 13:162-166

50. Banks JG, Foulis AK, Ledingham IM, Macsween RN: Liver function in septic shock. J Clin Pathol 1982, 35:1249-1252.

51. Kramer L, Jordan B, Druml W, Bauer P, Metnitz PGH: Incidence and prognosis of early hepatic dysfunction in critically ill patients--a prospective multicenter study. Crit Care Med 2007, 35:1099-1104.

52. Moreno R, Vincent JL, Matos R, Mendonça A, Cantraine F, Thijs L, Takala J, Sprung $C$, Antonelli M, Bruining $H$, Willatts $S$ : The use of maximum SOFA score to quantify organ dysfunction/failure in intensive care. Results of a prospective, multicentre study. Working Group on Sepsis related Problems of the ESICM. Intensive Care Med 1999, 25:686-696.

53. Moseley RH: Sepsis and cholestasis. Clin Liver Dis 2004, 8:83-94.

54. Assimakopoulos SF, Scopa CD, Vagianos CE: Pathophysiology of increased intestinal permeability in obstructive jaundice. World J Gastroenterol 2007 13:6458-6464.

55. Trauner M, Meier PJ, Boyer JL: Molecular pathogenesis of cholestasis. N Engl J Med 1998, 339:1217-1227.

56. Fuchs M, Sanyal AJ: Sepsis and cholestasis. Clin Liver Dis 2008, 12:151-172, ix

57. Deeley RG, Westlake C, Cole SPC: Transmembrane transport of endo- and xenobiotics by mammalian ATP-binding cassette multidrug resistance proteins. Physiol Rev 2006, 86:849-899.

58. Spirli C, Fabris L, Duner E, Fiorotto R, Ballardini G, Roskams T, Larusso NF, Sonzogni A, Okolicsanyi L, Strazzabosco M: Cytokine-stimulated nitric oxide production inhibits adenylyl cyclase and cAMP-dependent secretion in cholangiocytes. Gastroenterology 2003, 124:737-753.
59. Kamiya S, Nagino M, Kanazawa H, Komatsu S, Mayumi T, Takagi K, Asahara T, Nomoto K, Tanaka R, Nimura Y: The value of bile replacement during external biliary drainage: an analysis of intestinal permeability, integrity, and microflora. Ann Surg 2004, 239:510-517.

60. Padillo FJ, Muntane J, Montero JL, Briceño J, Miño G, Solorzano G, Sitges-Serra A, Pera-Madrazo C: Effect of internal biliary drainage on plasma levels of endotoxin, cytokines, and C-reactive protein in patients with obstructive jaundice. World J Surg 2002, 26:1328-1332.

61. Dellinger RP, Levy MM, Carlet JM, Bion J, Parker MM, Jaeschke R, Reinhart K, Angus DC, Brun-Buisson C, Beale R, Calandra T, Dhainaut JF, Gerlach H, Harvey M, Marini JJ, Marshall J, Ranieri M, Ramsay G, Sevransky J, Thompson BT, Townsend S, Vender JS, Zimmerman JL, Vincent JL: Surviving Sepsis Campaign: international guidelines for management of severe sepsis and septic shock: 2008. Crit Care Med 2008, 36:296-327.

62. Kubitz R, Wettstein M, Warskulat U, Häussinger D: Regulation of the multidrug resistance protein 2 in the rat liver by lipopolysaccharide and dexamethasone. Gastroenterology 1999, 116:401-410.

63. Moreno R, Sprung CL, Annane D, Chevret S, Briegel J, Keh D, Singer M, Weiss YG, Payen D, Cuthbertson BH, Vincent J: Time course of organ failure in patients with septic shock treated with hydrocortisone: results of the Corticus study. Intensive Care Med 2011, 37:1765-1772.

64. McClave SA, Martindale RG, Vanek VW, McCarthy M, Roberts P, Taylor B, Ochoa JB, Napolitano L, Cresci G: Guidelines for the Provision and Assessment of Nutrition Support Therapy in the Adult Critically III Patient: Society of Critical Care Medicine (SCCM) and American Society for Parenteral and Enteral Nutrition (A.S.P.E.N.). JPEN J Parenter Enteral Nutr 2009, 33:277-316.

65. Braga M, Gianotti L, Gentilini O, Parisi V, Salis C, Di Carlo V: Early postoperative enteral nutrition improves gut oxygenation and reduces costs compared with total parenteral nutrition. Crit Care Med 2001, 29:242-248.

66. Hu Q, Zheng Q: The influence of Enteral Nutrition in postoperative patients with poor liver function. World J Gastroenterol 2003, 9:843-846

67. Hegazi RA, Wischmeyer PE: Clinical review: optimizing enteral nutrition for critically ill patients - a simple data-driven formula. Crit Care 2011, 15:234.

68. de Vree JM, Romijn JA, Mok KS, Mathus-Vliegen LM, Stoutenbeek CP, Ostrow JD, Tytgat GN, Sauerwein HP, Oude Elferink RP, Groen AK: Lack of enteral nutrition during critical illness is associated with profound decrements in biliary lipid concentrations. Am J Clin Nutr 1999, 70:70-77.

69. Han MK, Hyzy R: Advances in critical care management of hepatic failure and insufficiency. Crit Care Med 2006, 34:\$225-231.

70. Hawker F: Liver dysfunction in critical illness. Anaesth Intensive Care 1991, 19:165-181.

71. Moyer AM, Fridley BL, Jenkins GD, Batzler AJ, Pelleymounter LL, Kalari KR, Ji Y, Chai Y, Nordgren KKS, Weinshilboum RM: Acetaminophen-NAPQI hepatotoxicity: a cell line model system genome-wide association study. Toxicol Sci 2011, 120:33-41.

72. Roma MG, Toledo FD, Boaglio AC, Basiglio CL, Crocenzi FA, Sánchez Pozzi EJ: Ursodeoxycholic acid in cholestasis: linking action mechanisms to therapeutic applications. Clin Sci 2011, 121:523-544.

doi:10.1186/cc11381

Cite this article as: Nesseler $\mathrm{N}$, et al.: Clinical review: The liver in sepsis. Critical Care 2012, 16:235. 